\title{
Poesía en la clausura. Celebración del ingreso y la profesión solemne en el Monasterio de Santa Catalina de Sena de Buenos Aires: 1861-1903
}

\author{
Poetry in Cloisters. Celebrating the Entrance and Solemn Profession \\ in the Dominican Monastery of Santa Catalina de Sena of Buenos Aires: \\ 1861-1903
}

\author{
Alicia Fraschina \\ UNIVERSIDAD DE BUENOS AIRES, aliciafraschina@gmail.com
}

En medio de una sociedad que busca reconfigurarse y en un contexto social adverso, a partir de la década de 1860, las monjas del Monasterio Santa Catalina de Sena de Buenos Aires toman la palabra: interpelan al discurso hegemónico y componen una serie de poemas. Con el propósito de homenajear a las ingresantes a la vida consagrada en la clausura escriben para hablar de sí, reconocerse, explicarse, para liberarse, para socializar y crear belleza. En este trabajo me propongo comprender el sentido profundo y analizar las formas de dicha expresión poética, una práctica de escritura excepcional en el ámbito conventual de Hispanoamérica durante el siglo XIX.

Palabras ClaVE: monjas, poesía, siglo XIX, secularización, Buenos Aires.

In the midst of a society seeking to redefine itself in an antagonistic social context, the decade of the 1860s found the nuns of Santa Catalina de Sena in Buenos Aires making their voices heard as they challenged the hegemonic discourse by composing a series of poems. Desirous of honoring the aspirants who had chosen the sacred life of the cloisters, they wrote to express, define, explain and free themselves; to socialize and create beauty. The aim of this paper is to understand the underlying meaning of the forms of their poetic expression and analyze this exceptional approach to writing in the context of Hispanic American nunneries in the $19^{\text {th }}$ century.

KEYwORDS: nuns, poetry, $19^{\text {th }}$ century, secularization, Buenos Aires.

Fecha de recepción del artículo: 22 de junio de 2015 / Fecha de aprobación: 29 de febrero de 2016 / Fecha de recepción de la versión final: 2 de marzo de 2016

a investigación en torno a la escritura de las monjas en el es-
pacio de la clausura - una escritura amplia y variada- lleva ya
décadas. Sin embargo es abundante el material que aguarda
ver la luz. El presente trabajo es una reflexión en torno a un corpus
de poemas, desconocidos hasta el momento, escritos a partir de 
1861, por las monjas dominicas del Monasterio Santa Catalina de Sena de Buenos Aires, Argentina. ${ }^{1}$ Un corpus de 30 poemas, entre los que hemos seleccionado los nueve que refieren a la toma de hábito y a la profesión solemne: el inicio de una nueva vida, de un viaje sin retorno, y de una nueva identidad, esposa de Jesucristo. ${ }^{2}$ Se trata de una práctica de escritura inédita, un sendero nunca transitado en dicho espacio porteño, fundado hacía más de un siglo, en 1745.

Con la intención de comprender el sentido de dichos poemas y los deseos que impulsan su escritura intentamos dar respuesta a una serie de cuestiones: cuál es la situación de enunciación que da lugar a su producción; quiénes los escriben y a qué audiencia están destinados; qué elementos de la tradición poética retoman; cuál es la estructura y el código semántico al que apelan; qué nivel de autoconocimiento y de conocimiento del mundo y del huerto cerrado muestran las autoras. Si bien, los motivos invocados nos hacen pensar que son poemas de experiencia directa de la vida dentro de la clausura, cabe preguntarnos si no está también presente en ellos cierto misticismo.

Según afirma Michel de Certeau, "la expresión literaria no es la transparencia de la vida social, sino su complemento y a menudo su revés, en la medida en que enuncia lo que se percibe como faltante". ${ }^{3}$ ¿No es ésta acaso la cuestión que nos convoca?

${ }^{1}$ Agradezco a sor María de la Cruz, actualmente priora del Monasterio de Santa Catalina de Siena, San Justo, Provincia de Buenos Aires, Argentina, quien estando a cargo del Archivo (en adelante AMSCS) me dio a conocer los poemas sobre los que reflexiono en este trabajo. Y a Victoria Cohen Imach y Lucas Margarit quienes me sugirieron senderos para comenzar a transitar el camino del análisis de la poesía conventual. Sobre el Monasterio de Santa Catalina de Sena durante el periodo colonial -1745-1810 - véase Alicia Fraschina, Mujeres consagradas en el Buenos Aires colonial (Buenos Aires: EudEBA, 2010) y Gabriela Braccio, "Una ventana hacia otro mundo. Santa Catalina de Sena: primer convento femenino de Buenos Aires", Colonial Latin American Review 9(2) (2000): 187-211. Para el siglo XIX véase Alicia Fraschina, "Reinventar la vida cotidiana en la clausura. Una tarea de las monjas dominicas de Buenos Aires en el siglo xix", Itinerantes, Revista de Historia y Religión (1) (2011): 91-115.

${ }^{2}$ Se trata de una serie de treinta poemas inéditos de los cuales sólo se han dado a conocer muy contadas estrofas en Enrique Udaondo, Reseña histórica del Monasterio de Santa Catalina de Sena de Buenos Aires (Buenos Aires: Talleres Gráficos San Pablo,1945), 105107. Para más datos sobre los 9 poemas seleccionados véase el Apéndice de este artículo.

${ }^{3}$ Michel de Certeau, La escritura de la historia (México: Universidad Iberoamericana, 1993), 44. 
Los primeros poemas de la serie que analizamos se escriben en medio de una sociedad que busca reconfigurarse después de décadas de enfrentamientos, producto de la crisis monárquica, del paso del Antiguo Régimen a la Modernidad, de revoluciones y profundas reformas institucionales. La fecha de 1861, en la que comienzan a producirse estos testimonios, no es casual. La Constitución de 1853 proclamó la vigencia del sistema republicano dando inicio a un proceso que llevará años y conducirá a la República Argentina unificada en 1862. Una República que contará con su contrapunto en el terreno religioso: la creación de la arquidiócesis de Buenos Aires en 1865, para la que es designado Mariano José de Escalada. ${ }^{4}$

Al mismo tiempo que se producen estas transformaciones, desde mediados de siglo se hace cada vez más evidente la progresiva secularización ${ }^{5}$ de la sociedad porteńa, la paulatina autonomía del discurso político del religioso, y el desarrollo de cierto rechazo de los círculos políticos liberales hacia determinadas modalidades del catolicismo. La Iglesia es visualizada por algunos sectores como una rémora del pasado. Cada vez más, la cultura, la educación y la información se traducen en actitudes críticas hacia ella.

${ }^{4}$ Mariano José de Escalada y Bustillo Ceballos (1799-1870) es nombrado obispo de Buenos Aires en 1855. Visita la diócesis y sale a misionar con los jesuitas, obliga al clero a hacer ejercicios espirituales y a asistir a conferencias de moral que tienen lugar tres veces al mes, redacta varias cartas pastorales sobre diferentes temas y erige dieciocho nuevos templos en espacios donde la población ha aumentado notablemente. En una quinta heredada de su padre organiza el seminario de Buenos Aires que confía a los jesuitas. En 1865, la diócesis de Buenos Aires fue elevada a arquidiócesis primada: Escalada fue su primer arzobispo.

${ }^{5}$ Sobre el proceso de secularización en este periodo véase Valentina Ayrolo, María Elena Barral, Roberto Di Stefano, Catolicismo y secularización. Argentina, primera mitad del siglo XIX (Buenos Aires: Editorial Biblos, 2012). En torno a dicho proceso en los espacios de religiosidad femenina en Buenos Aires véase en dicha publicación el capítulo de Alicia Fraschina, "El proceso de secularización en los monasterios de monjas y en la Casa de Ejercicios y Beaterio de Buenos Aires, 1750-1865", en Catolicismo y secularización. Argentina, primera mitad del siglo XIX, coord. Valentina Ayrolo, María Elena Barral, Roberto Di Stefano, 39-64. Buenos Aires: Editorial Biblos, 2012. Compartimos la afirmación de Roberto Di Stefano en torno a la secularización: "Lo que se discute no es la validez o no de las creencias religiosas, sino el lugar que ocupan las instituciones y la jerarquía eclesiástica dentro de la sociedad argentina en rápida transformación", véase Roberto Di Stefano y Loris Zanatta, Historia de la Iglesia argentina. Desde la Conquista hasta fines del siglo XX (Buenos Aires: Grijalbo Mondadori, 2000), 280. 
Por su parte, el catolicismo avanza hacia posiciones de mayor intransigencia y reformula su lugar en la sociedad: un proceso que se observa no sólo en la Argentina, sino en todo el orbe católico. ${ }^{6} \mathrm{Ve}$ con profundo fatalismo - presente muy especialmente en la prensa periódica, los escritos y los sermones de un sector del clero- el avance del proceso de secularización.

Vale recordar la intervención del dominico de origen irlandés Antonio Domingo Fahy, instalado en Buenos Aires, quien en 1861 en carta dirigida al cardenal Alejandro Barnabó se lamenta que la filosofía del siglo anterior, así como la literatura inmoral de Francia, hayan corrompido de tal suerte los ánimos de casi todos, al punto que su generación carece en absoluto de ideas religiosas. Como consecuencia-comenta- los padres no permiten a sus hijos ingresar al clero, o al convento en el caso de las mujeres, y desalientan, cuando las hay, las intenciones de seguir una carrera que se considera impropia de los nuevos tiempos. ${ }^{7}$

Es más, cuando en mayo de 1856, un grupo de mujeres de la sociedad porteńa solicita autorización para fundar un monasterio de monjas carmelitas de clausura, el dictamen del fiscal es terminante: "No habiendo necesidad ni conveniencia alguna social para aumentar los conventos de monjas que hay en la ciudad, no ha lugar a la solicitud de las suplicantes". ${ }^{8}$ Lo que a su juicio parece más conveniente es la apertura de un establecimiento en el que las religiosas se dediquen a remediar las necesidades de su prójimo.

${ }^{6}$ Véase Juan María Laboa, Historia de la Iglesia. IV: Época contemporánea, capítulos I a x (Madrid: Biblioteca de Autores Cristianos, 2002). El pontificado de Pío IX (18461878) tiende desde 1848 a acentuar la crítica al liberalismo y a centralizar en Roma las instancias de decisión. Prevalecen en las orientaciones pontificias la intransigencia, el ultramontanismo y la centralización. Se afirma el poder de jurisdicción del papa sobre toda la Iglesia y se proclama su infalibilidad en materia doctrinal y dogmática en la Constitución Dei Filius del Concilio Vaticano I (1869-1870).

${ }^{7}$ Véase Di Stefano y Zanatta, p. 276.

${ }^{8}$ Archivo General de la Nación (AGN), Buenos Aires, Argentina, sala x, 28.9.4., exp. 12.131. Ministerio de Gobierno. 31 de mayo de 1856. Doña Paulina López Seco y otras varias Señoras piden se les permita, previo los trámites correspondientes, fundar un convento de monjas con el título de Santa Teresa de Jesús. Finalmente en 1873 se logrará la fundación del monasterio de las carmelitas de clausura en Buenos Aires. 
Ante el embate liberal secularizante, el catolicismo se repliega sobre sí mismo. En consecuencia, a la prensa liberal se opone la prensa católica -La Religión, El Orden, El Pensamiento Argentino, El Estandarte Católico, creados entre 1853 y 1864-; a los clubes liberales, el Club Católico. Al mismo tiempo nuevas congregaciones llegan al país-Hermanas de la Misericordia, Hermanas del Huerto, Hijas de la Caridad, Padres lazaristas y bayoneses-, y otras antiguas -como los jesuitas y los franciscanos dependientes de la Sacra Congregación de Propaganda Fide- se incorporan y contribuyen a crear para el catolicismo un mundo a su medida: una escuela y una atención hospitalaria confesionales, diversos ámbitos de sociabilidad para los creyentes - por ejemplo, el Club Católico en 1877, la Acción Católica en 1883- y canales de difusión de la buena prensa.

En gran medida, los esfuerzos por reorganizar las instituciones eclesiásticas parten de los obispos quienes llevan adelante la romanización de la Iglesia católica en Argentina, un proceso que impone por décadas una disciplina eclesiástica más rígida y conduce a la concentración del poder dogmático, doctrinario y disciplinario en el pontífice y su curia. ${ }^{9}$

La progresiva secularización de la sociedad y la romanización de la Iglesia son conocidas por las monjas del Monasterio de Santa Catalina de Sena a través de las visitas canónicas que lleva a cabo el prelado porteño y de los sermones pronunciados en ocasión de las ceremonias de toma de hábito y de profesión. Sermones en los que los oradores asumen una actitud combativa y denuncian la tensión creada entre "el mundo" -con su fe absoluta en la racionalidad positivista y en el progreso material - y la vida consagrada en la clausura, que algunos sectores ven como un "sacrificio inútil". ${ }^{10}$

\footnotetext{
${ }_{9}^{9}$ Para la contextualización del periodo analizado nos hemos basado en Di Stefano y Zanatta, pp. 269-353.

${ }^{10}$ A modo de ejemplo citamos: Sermón pronunciado en el Monasterio de las Monjas Catalinas con motivo de la solemne profesión religiosa que hizo Sor María de Jesús, llamada en el siglo Da. Genoveva Constanzó, por el Reverendo Padre Prior del Convento de Santo Domingo Fr Ventura Martinez, en 23 de enero de 1862 (Imprenta de la "Revista", 1862), 1-23. AMSCs, Discurso pronunciado en el Monasterio de Catalinas de Buenos Aires por el Canónigo Piñero en el dia de la solemne profesión de su sobrina la hermana María Ana de Jesús llamada en el siglo Da. María Simodocia Piñero (Buenos Aires: Imprenta el Nacional, 1862).
} 
Los autos de las visitas canónicas al monasterio -visitas que lleva a cabo el obispo Mariano Escalada entre 1856 y 1863-, ${ }^{11}$ realizadas por primera vez cada tres años, tal como lo ordenaba la norma tridentina, permiten conocer las intenciones reformadoras del prelado: pretende que las religiosas cumplan con la Regla de San Agustín y las Constituciones de las Monjas Dominicas que han prometido obedecer-lo que supone un mayor alineamiento con Roma-; y "se olviden del mundo que abandonaron al profesar", una aspiración a hacer del huerto cerrado una institución más autónoma de la sociedad. En consecuencia, impone el silencio y el recogimiento, la obediencia a la prelada y a las oficialas; auspicia la práctica de la humildad y el abandono de ciertas prácticas como la excesiva familiaridad en el trato; enfatiza la adhesión a la pobreza; recuerda la obligatoriedad de la vida común; ${ }^{12}$ y el respeto al orden jerárquico -según la antigüedad en la orden-.

Es justamente a partir de la década de 1860, un momento de redefiniciones en el espacio político y en el eclesiástico, de enfrentamientos entre principios liberales e intransigentes, y de reacomodamientos que conducirán hacia la Argentina moderna, que las monjas dominicas de Buenos Aires toman la palabra y forjan sus relatos a través de la poesía.

Las autoras forman parte de una tradición escrituraria de muy larga data dentro de la Iglesia, tanto en Europa como en América. Ya en la Edad Media algunas mujeres escriben sobre sus experiencias espirituales y sus producciones son actualmente leídas y objeto de un profundo análisis. ${ }^{13}$ En España, la escritora típica de la Edad

${ }^{11}$ Amscs, Auto de visita del Dr. Don Mariano José de Escalada y Bustillos Cevallos, Obispo de la Santísima Trinidad de Buenos Aires, 10 de septiembre de 1856; Ibidem, 18 de septiembre de 1860; Ibidem, 25 de septiembre de 1863.

${ }^{12}$ La vida común había sido derogada - por razones económicas- por el auto de visita de 1823 como consecuencia de las "reformas rivadavianas" impulsadas desde el gobierno y desde la cúpula de la Iglesia porteńa: AMscs, Auto de visita del Provisor Mariano Zavaleta al Monasterio de Catalinas, 22 de febrero de 1823; y retomada a partir de una decisión conjunta de las monjas y el obispo Escalada en 1861: AMscs, Auto de vida común. Dr. Don Mariano José de Escalada y Bustillo Cevallos, Obispo de esta Diócesis de la Santísima Trinidad de Buenos Aires, 31 de mayo de 1861.

${ }^{13}$ Véase Francis Beer, Women and the Mystical Experience in the Middle Ages (Woodbridge: The Boydell Press, 1992). Elizabeth Petroff, Medieval Women's Visionary Literatu- 
Moderna fue una monja. La escritura estaba íntimamente ligada a la vida conventual: las cartas, la narrativa del yo, los relatos de fundación, la hagiografía, producen textos que se mueven entre la oralidad y la escritura. Textos que en general no se imprimieron, y sólo circularon en el interior de los conventos y en ocasiones sufrieron el control y la condena de la Inquisición. ${ }^{14}$

En el Nuevo Mundo, la escritura de religiosas comienza en el siglo XVI y florece en el XVII, es en su gran mayoría anónima, y ha permanecido prácticamente inédita en archivos conventuales y privados.

La investigación en torno a dicha escritura religiosa femenina, el género de mayor auge en la actualidad en el ámbito de la historiografía de las mujeres religiosas, se inició a mediados de la década de 1980. ${ }^{15}$ Durante años, los escritos de las monjas se excluyeron del canon literario con la excusa de que se trataba de "textos de religión”. Hoy en día, el protagonismo de los estudios culturales ha ayudado a su legitimación. La historia y la literatura posaron su mirada sobre los escritos de las mujeres consagradas a Dios - monjas y beatas- casi al mismo tiempo. Las autobiografías, las biografías y los epistolarios -siguiendo la categorización propuesta por Asunción Lavrin y Rosalva Loreto López- son objeto de análisis y de

re (Nueva York: Oxford University Press, 1986). Victoria Cirlot y Blanca Garí, La mirada interior. Escritoras misticas y visionarias en la Edad Media (Barcelona: Ediciones Martínez Roca, 1999).

${ }^{14}$ Véase Ronald Surtz, Writing Women in Late Medieval and Early Modern Spain. The Mothers of Saint Teresa of Avila (Filadelfia: University of Pennsylvania Press, 1995). Cristina Segura Graińo, ed., La voz del silencio. Fuentes directas para la historia de las mujeres (siglos VIII-XVIII) (Madrid: Asociación Cultural Al-Mudayna, 1992). Electa Arenal y Stacey Schlau, Hispanic Nuns in their Own Works (Albuquerque: University of Mexico Press, 1989). Para un estado de la cuestión actualizado, véase Nieves Baranda Leturio y Ma. Carmen Marín Pina, eds., Prólogo, "El universo de la escritura conventual femenina: deslindes y perspectivas", en Letras en la celda. Cultura escrita de los conventos femeninos en la España moderna (Madrid y Frankfurt: Iberoamericana-Vervuert, 2014), 11-45. El proyecto BIESEs (Bibliografía de Escritoras Españolas http://www.bieses), dirigido por Nieves Baranda, constituye una herramienta fundamental para la información en torno a la escritura conventual de más de 300 autoras monjas.

${ }^{15}$ Entre los trabajos pioneros en torno al tema véase Josefina Muriel, Cultura femenina novohispana [1ª ed. 1982] (México: Universidad Nacional Autónoma de México, 1994), 313-471. 
numerosas publicaciones-. ${ }^{16}$ Una escritura que se produce en ocasiones como mandato de los confesores, en otras, como vía de expresión de la compleja realidad espiritual de las religiosas. Kathleen Myers sugiere una categorización diferente-en cuatro áreas-al referirse a dicha producción historiográfica. Una categorización que contempla el estudio de "vidas espirituales"; el uso de estrategias retóricas; el rol de los escritos religiosos femeninos en la construcción de la identidad criolla; y la inclusión de los mismos en un contexto más amplio a fin de compararlos con los de escritores seculares. ${ }^{17}$

Dentro de esta producción, la poesía, con la excepción de sor Juana Inés de la Cruz, no fue el género literario más cultivado por las monjas. ${ }^{18}$ Sin embargo, en los últimos ańos se han localizado poemas escritos por religiosas desde México hasta Córdoba -en la actual Argentina-, poemas que están siendo difundidos y analizados. ${ }^{19}$

\footnotetext{
${ }^{16}$ Asunción Lavrin y Rosalva Loreto López, eds., Monjas y beatas. La escritura femenina en la espiritualidad barroca novohispana. Siglos XVII y XVIII (México: Universidad de las Américas-Puebla, Archivo General de la Nación, 2002). Asunción Lavrin y Rosalva Loreto López, eds., Diálogos espirituales. Manuscritos femeninos hispanoamericanos. Siglos $X V I-X I X$ (México: Universidad Autónoma de Puebla, Universidad de las Américas-Puebla, 2006). Asunción Lavrin, "Los senderos interiores de los conventos de monjas", Boletín de Monumentos Históricos, 3a Época (30) (enero-abril 2014): 6-21.

${ }^{17}$ Kathleen Ann Myers, "Crossing Boundaries: Defining the Field of Female Religious Writing in Colonial Latin America”, Colonial Latin American Historical Review 9(2) (2000): 151-165.

${ }^{18}$ Asunción Lavrin, Brides of Christ. Conventual Life in Colonial Mexico (Stanford: Stanford University Press, 2008), 313. Con motivo del tercer centenario de la muerte de sor Juana Inés de la Cruz se multiplicaron las publicaciones en torno a su obra, sólo a modo de ejemplo, véase Margo Glantz, Sor Juana Inés de la Cruz: ¿Hagiografía o autobiografia? (Mexico: Grijalbo, unam, 1995). Marie Cécile Bénassy-Berling, "Actualidad del sorjuanismo (1994-1999)", Colonial American Historical Review 9 (2) (2000): 277-292.

${ }^{19}$ Sobre el tema, véase Íride María Rossi de Fiori, Rosanna Caramella de Gamarra, Soledad Martínez de Lecuona, Helena Fiori Rossi, La palabra oculta. Monjas escritoras en la Hispanoamérica colonial (Salta: Ediciones Universidad Católica de Salta, Editorial Biblioteca de Textos Universitarios, 2008). Asunción Lavrin y Rosalva Loreto López, eds., Diálogos espirituales, especialmente Nela Río, "Me hizo pensar cosa no pensada. La poesía de sor Leonor de Ovando (1548?-1612?)”, pp. 386-419. Jennifer Eich, The Other Mexican Muse. Sor María Águeda de San Ignacio (1695-1756) (Nueva Orleans: University Press of the South, 2004). Elia Armacanqui-Tipacti, Sor Maria Manuela de Santa Ana. Una teresiana peruana (Cuzco: Centro de Estudios Regionales Andinos "Bartolomé de las Casas", 1999). Kathryn Joy McKnight, The Mystic of Tunja. The Writings of Madre Castillo, 1671-1742 (Amherst: University of Massachusetts Press, 1997). Raïssa Kordic
} 
La poesía escrita para las tomas de velo -afirma Nieves Baranda Leturio- es uno de los subgéneros frecuentes en las escritoras conventuales más prolíficas de España, en especial, en las zonas de Barcelona y Zaragoza. Podríamos remontar su inicio conocido a Teresa de Jesús, que entre sus 28 poemas tiene cinco dedicados a las profesiones. Una tradición compositiva que se perpetúa en el Carmelo, aunque de ningún modo se limita a esta orden. El villancico, que ya estaba integrado en la tradición musical litúrgica, será el que predomine en sus muchas variantes. ${ }^{20}$ Una tradición que cruza el Atlántico y se recoge en Hispanoamérica. En México, sor Juana Inés de la Cruz compone un villancico en ocasión de una profesión religiosa:

\section{Estribillo}

Zagalejos de la Aldea,

Venid a ver una Boda,

Y no quede en ella toda

Quien su festejo no vea:

Ved, que el Mayoral se emplea

En una pobre Pastora,

Que de hoy [en] más será Señora;

Pues con él se ha desposado.

Este sí que es enamorado,

Como lo he menester yo;

Este sí, que los otros no.

Riquelme, Epistolario de sor Dolores Peña y Lillo (Chile, 1763-1769) (Madrid, Frankfurt y Main: Universidad de Navarra, Iberoamericana-Vervuert, 2008), 504-511.

${ }^{20}$ Véase Nieves Baranda Leturio, "Cantos al sacro epitalamio o sea pliegos poéticos para las tomas de velo. Deslindes preliminares", Bulletin Hispanique, tomo 113(1) (junio 2011): 269-296. Se trata de un estudio inaugural de 182 pliegos sueltos de villancicos impresos en España hasta 1749 con motivo de las profesiones religiosas en conventos femeninos. Nieves Baranda Leturio, "Producción y consumo poéticos en los conventos femeninos”, Bulletin Hispanique, tomo 115(1) (junio 2013): 165-183. Las tomas de velo eran las ceremonias comunes más importantes. En ellas parece que eran imprescindibles los villancicos, al menos desde la segunda mitad del siglo xvir, incluidos como parte de la ceremonia y cantados por las monjas y por ejecutores profesionales: 174 . 


\section{Coplas}

De tanta fortuna goza,

Cuando de culpas se lava,

Que ella se confiesa Esclava,

Y él la ama como Esposa:

Ella en sus plantas reposa,

Y Él la ofrece su Costado,

Este sí, que es enamorado.

En ella su ser retrata,

Y tal Castidad la inspira,

Que es más Casta si le mira;

Y más limpia si le trata:

Paga su amor abrazado. ${ }^{21}$

Retornando al Monasterio Santa Catalina de Sena de Buenos Aires, interesa saber en primer lugar quiénes son concretamente las autoras de los poemas sobre los que estamos reflexionando. Tal vez, como consecuencia de una opción deliberada por el anonimato, la mayoría de ellos no lleva el nombre de la religiosa que lo compuso. De los nueve que conforman el corpus que analizamos, tres son atribuidos -ya en el siglo xx- a sor Cayetana del Santísimo Sacramento ${ }^{22}$ y dos -escritos en 1903- tienen el nombre de su respectiva autora al pie: sor Mercedes de Santo Domingo y sor María Dominga del Rosario Correa, ambas provenientes de Córdoba. ${ }^{23}$

${ }^{21}$ Sor Juana Inés de la Cruz, Poesías lírico sacras (según la edición de Barcelona de 1693). Letras Sagradas en la solemnidad de la Profesión de una Religiosa, Letra I, en Íride María Rossi de Fiori, La palabra oculta, 379-380.

22 Sor Cayetana del Santísimo Sacramento, en el siglo Francisca Albín y Villegas, profesó como monja de coro en el Monasterio de Santa Catalina de Sena de Buenos Aires el 28 de septiembre de 1854. Ese día el sermón estuvo a cargo del presbítero Dr. Federico Aneiros, quien años más tarde será el segundo arzobispo de Buenos Aires. Había nacido en Montevideo el 19 de febrero de 1827, su madre dońa Anastasia Villegas casó en segundas nupcias con don Tomás de Gomensoro, primer presidente constitucional del Uruguay. Falleció en 1911.

${ }^{23}$ AMsCs, sor Mercedes de Santo Domingo Olmos nació en Córdoba en 1876 y profesó en 1898, fue electa priora en 1928, 1934 y 1945. Sor María Dominga del Rosario 
Si bien, la escritura se pone en marcha a partir del deseo de homenajear a una ingresante o a una novicia en el día de su toma de hábito o profesión, debemos bucear otras razones.

Una vez más Michel de Certeau ilumina nuestra reflexión:

¿qué es escribir? -se pregunta-. El laboratorio de la escritura tiene una función "estratégica": sea que una información recibida de la tradición o del exterior se encuentre allí recopilada, clasificada, imbricada con un sistema y de ese modo transformada, sea que las reglas y los modelos elaborados en este lugar exceptuado permitan actuar sobre el medio ambiente para transformarlo. ${ }^{24}$

Veamos si estamos ante una escritura estratégica, que recopila tradiciones y aspira a transformar el espacio conventual y eventualmente la sociedad porteña.

Las dominicas de Buenos Aires escriben por una serie muy amplia de motivos: para reconocerse y explicarse, para crear belleza, para hacer de los poemas un lugar donde la intimidad pueda llegar a desplegarse sin miedo, para liberarse, muy especialmente para hablar de sí. Con motivo de una toma de hábito sor Cayetana escribe:

Día grande de fausta memoria

Del que nunca olvidarme pudiera

$\mathrm{Su}$ recuerdo me sigue doquiera

Por él es mi existencia feliz. (Poema 2, estrofa 3$)^{25}$

Escriben para conmover, para transmitir su experiencia directa, para unirse más a Dios. ${ }^{26}$ Para crear una literatura ejemplar destina-

Correa nació en Córdoba en 1877 y profesó en 1896, fue electa priora en 1917, 1925 , 1931 y 1941.

${ }^{24}$ Michel de Certeau, La invención de lo cotidiano. 1 Artes de hacer (México: Universidad Iberoamericana, 1996), 149.

${ }^{25}$ Para cada cita de poemas y estrofas remito a los datos contenidos en el Apéndice. En todos los casos conservo la ortografía original.

${ }^{26}$ Con respecto al tema Henri Bremond comenta: "Por medio de las ideas que expresa, o mejor, de las expresiones que emplea, el poeta no tiene el propósito de enseńarnos algo, sino de transmitirnos cierto sacudimiento, de arrastrarnos a cierta experiencia, de 
da a moldear el carácter de las profesas; para fortalecer el proceso de adquisición de la nueva identidad ${ }^{27}$-mujer consagrada, esposa de Cristo-, el acontecimiento disparador de esta escritura en un contexto social adverso:

Eres virgen prudente

Tienes la mejor parte

Supiste conquistarte

De un Rey la voluntad

Y ya que desposada

Con él te contemplamos

Todas felicitamos

Tu augusta dignidad (Poema 1, estrofa 1)

Para establecer un vínculo de mutuo afecto entre las religiosas:

Sor Mariana mi hermana querida

Yo no sé qué decirte este día

Pues de veras es tal mi alegría

Que ella misma embaraza mi voz (Poema 2, estrofa 1)

Para recoger tanto la tradición precedente -desde la Biblia a san Juan de la Cruz y Teresa de Jesús- como los desafíos que les propone el siglo XIX.

Escriben muy probablemente en la celda, ese cuarto propio, espacio de privacidad, lugar privilegiado para la composición poética.

Componen poemas que tienen por destinataria directa a la recién llegada, pero también a sus compañeras de vida: las monjas de la comunidad dominicana. Es una escritura de mujeres para mujeres, destinada a una audiencia homogénea capaz de comprender

elevarnos a cierto estado". Henri Bremond, Plegaria y poesía (Buenos Aires: Editorial Nova, 1947), 79.

${ }^{27}$ En torno a la función didáctica de la poesía véase Elisabetta Graziosi, "Scrivere in convento: devozione, encomio e persuasione nelle rime delle monache fra Cinque e Seicento", en Donna, disciplina, creanza cristiana dal XVI al XVII secolo. Studi e testi a stampa, ed. Gabriella Zarri, 303-331 (Roma: Edizioni di Storia e Letteratura, 1996). 
ciertas referencias que parecen demandar la cooperación de un lector informado.

Son poemas escritos para ser leídos en la intimidad de la clausura una vez terminada la ceremonia de ingreso o de profesión. ${ }^{28}$ Una lectura oralizada, teatralizada, una práctica encarnada en gestos, espacios y costumbres, destinada a un auditorio restringido. Una lectura en voz alta que muy probablemente sugiere el comentario, realizada para homenajear, enseñar, pero también por el placer del intercambio, por el beneplácito de la relación así establecida. Pasatiempo, diversión y una forma de cimentar la sociabilidad. ${ }^{29}$

Ignoramos si estos poemas circulaban entre las profesas una vez terminado el festejo. Pero no cabe duda que su valor ha sido reconocido, pues, se encuentran entre las fuentes del Archivo del Monasterio, en folios sin numerar, y han sido copiados con una misma caligrafía, con la clara intención de conservar su memoria. Una transcripción que nos impide hoy acceder a los textos originales -que ignoramos si se han conservado-, conocer el proceso de composición, saber cuántas autoras se esconden detrás de esta serie. Uno de ellos -Poema 8- está enmarcado por un trabajo de calado artesanal, característico de los poemas del Carmelo de la ciudad de Córdoba, Argentina. ${ }^{30}$

Estamos ante poemas de estructura muy simple y básica. Pero cabe pensar que eso es justamente lo que se busca-recordemos-se trata de

${ }^{28}$ Agradezco a sor María de la Cruz esta información. Sobre la costumbre de una celebración íntima una vez terminada la función pública en los conventos de la Nueva España véase Asunción Lavrin, Brides of Christ, 55. Una celebración privada como parte de las ceremonias de profesión -en los que se interpretan diferentes géneros, loas, sobre todo- también se encuentra en Espańa. Véase Nieves Baranda Leturio, "Cantos al sacro epitalamio", 271.

${ }^{29}$ Véase Roger Chartier, El mundo como representación. Historia cultural: entre práctica y representación (Barcelona: Editorial Gedisa, 1995), 107-120.

${ }^{30}$ Este enmarcado en trabajo artesanal es una característica presente en todos los poemas escritos en el Carmelo de Córdoba (Argentina) a comienzos del siglo xIx. Se trata de una artesanía con papel que en México existió desde siempre, lo que dio lugar a un verdadero arte popular que aún se mantiene. Véase Íride María Rossi de Fiori, Rosanna Caramella de Gamarra, Helena Fiori Rossi, Primera escritura femenina en la República Argentina. Poemas del Carmelo de Córdoba (1804), 2a ed. (Salta: Biblioteca de Textos Universitarios, 2000), 52. En torno al monasterio Santa Teresa de Jesús, de las Carmelitas Descalzas de Córdoba -fundado en 1628- véase Cayetano Bruno, sDB, Historia de la Iglesia en la Argentina, 12 vols., vol. 2 (Buenos Aires: Editorial Don Bosco, 1966-1981), 543-550. 
autoras que se han propuesto alejarse del mundo. ${ }^{31}$ No encontramos en ellos elementos que nos permitan pensar en influencia alguna de la literatura del siglo xIx: del romanticismo, el realismo (influido por el positivismo) y el modernismo, de los cuales se ven claras huellas en la producción literaria de distintas escritoras seglares seleccionadas por Nina Scott. ${ }^{32}$ Movimientos que las monjas muy probablemente desconocían. Todo parece indicar que han quedado ancladas en una tradición más antigua o más primitiva por su simpleza.

Son poemas directos, una actitud que se relaciona con la necesidad de "diálogo", de comunicación con la destinataria del poema:

\section{A mi querida hermanita Sor María Cecilia de Santa Rosa}

Canta canta feliz este día

Que alejada del mundo falaz

Has allado en el claustro que ansiabas

El consuelo, la dicha y la paz.

Canta canta carísima hermana

Que contigo también yo lo haré

Y alabando al Esposo divino

Gracias mil como tú le dare. (Poema 8, estrofa 1)

¿Una invitación a expresarse por el canto, a entonar el poema, tal como ocurría con los villancicos de toma de velo en Espańa?33 Un interrogante para el cual por el momento no he encontrado respuesta.

${ }^{31}$ Por el contrario, los poemas escritos por las monjas del Carmelo de Córdoba en 1804 con motivo de la muerte de fray José Antonio de San Alberto -quien ha sido obispo de Córdoba entre 1780 y 1785- evidencian influencia de la Ilustración a través de su adhesión a la escuela neoclásica -imbuida de un pensamiento liberal y laico-. Una escritura que participa indudablemente de los movimientos o escuelas literarias vigentes. Un tema abordado por Rossi de Fiori et al., "Las últimas escritoras religiosas de la Colonia, primeras en Argentina”, en La palabra oculta, 209-308.

${ }^{32}$ En relación con los movimientos literarios en boga en Hispanoamérica durante el siglo XIX y los géneros que usan las escritoras véase Nina Scott, "Escritoras hispanoamericanas del siglo XIX", en Historia de las mujeres en España y América Latina, vol. III, dir. Isabel Morant, 692-719 (Madrid: Cátedra, 2006).

${ }^{33}$ Véase Nieves Baranda Leturio, "Cantos al sacro epitalamio", 274 y 286. Los villan- 
Las metáforas que emplean -el convento como puerto seguro, los votos como anclas, la completa unión con Jesucristo como desposorio místico- tan necesarias para materializar la imagen, son claras, tienen un mismo código semántico frente a temas religiosos, lo que hace de estos poemas textos de fácil interpretación para la audiencia a la que están destinados. Es que se trata de códigos aprendidos durante el año de noviciado -el periodo de formación-; y reactualizados tanto a través de las lecturas compartidas en el coro, el refectorio y la sala de labor, como de los sermones pronunciados por los frailes y presbíteros durante la misa diaria y las ceremonias de toma de hábito y de profesión.

Con respecto a la métrica, estamos en general -7 de los 9 poemas- ante composiciones escritas en verso de arte menor, una forma de verso característica de la poesía popular. Pero también hay dos escritos en versos endecasílabos, un verso de arte mayor, más culto.

Una de las cuestiones más interesantes para analizar estos textos es qué personas gramaticales usan:

— invocan el "tú", se homenajea al interlocutor directo:

Palpitar tu corazón

De encantadora alegría

Veo hermana en este día

Y en ello tienes razón.

Has adquirido un blasón

Un timbre habéis alcanzado

A una altura habéis llegado

Que mayor no puede haber

En fin has llegado hacer

Del cielo la admiración. (Poema 4, estrofa 4)

cicos para las profesiones estaban, como los navideños, destinados a un acto litúrgico de carácter comunitario, donde la música en romance era parte de una celebración festiva. Lamentablemente, los ceremoniales no indican dónde o cómo se insertaba la música vernácula, que es la que recogen los villancicos. 
— hay espacio para la focalización del "yo", quien relata la experiencia ya vivida y anuncia la nueva vida a la novicia o a la recién profesa:

De los años el yelo no puede Apagar el incendio que siento

$\mathrm{Al}$ recuerdo del dulce momento

Que este claustro querido pise.

Y mi pecho brotando delicias

En transporte de jubilo santo

Palpitando de amor y de encanto

Yo me siento impulsada a exclamar

Eden santo mansión deliciosa

Te saludo cien veces y más

En ti sólo se goza de calma

Y se tiene la suerte de amar. (Poema 8, estrofas 2, 3 y 4 )

— el "yo" sujeto de la enunciación en el que la autora asume la voz de la que acaba de profesar:

Con amarras bien fuertes

Estáis asegurada

Ya en la playa deseada

Hallaste tu placer (Poema 3, estrofa 2)

— hay un tercer uso del "yo" en el que se le cede la voz a Jesucristo que le habla a la nueva desposada:

Entre agudos dolores

De tres clavos pendientes

Te mostré finalmente

Hasta donde te amé (Poema 3, estrofa 14)

— el "nosotras" -inclusivo-, que refiere la vida en comunidad, entre iguales, en oposición al "ellos" que pertenecen al afuera: 
Si fuiste muy discreta

Y aunque el mundo te llame

Desamorada infame

Como os quiera llamar

Nosotras que sabemos

Valorar tu fortuna

Vemos que no hay ninguna

Que la pueda igualar. (Poema 1, estrofa 2)

— el "él”, la tercera persona, es referida a Jesucristo:

Ya ves que él hizo por vos

Lo que nadie hacer pudiera

Él te coloca en la esfera

De sus esposas queridas (Poema 4, estrofa 4)

¿Cuáles son los tópicos sobre los cuales escriben? La temática elegida permite ver a través de sus propias palabras el universo -idealizado tal vez- de las monjas de Buenos Aires durante la segunda mitad del siglo xIx. No estamos ante una temática original, sino que escriben a partir de modelos preexistentes. Recurren una y otra vez a ciertos topoi de la escritura conventual, una escritura que aspira a ser canónicamente correcta.

Mediante claras referencias a la toma de hábito y a la profesión, fortalecen a través de la poesía el proceso de adquisición de una nueva identidad. Una identidad tan sublime que hasta podría suscitar "la envidia de los ángeles":

Los ángeles pulsan hoy

Con dulcísima armonía

Sus cítaras y a porfía

Todos vienen a cantar.

Los parabienes a dar

Por su himeneo dichoso

A la que obtuvo un esposo

Que si ellos capaces fueran 
De envidia, se la tuvieran

Por favor tan singular. (Poema 4, estrofa 1)

Y describen el camino recorrido -la vida como un viaje- comenzando por el rechazo del mundo. Un mundo que visualizan como un mar peligroso:

Hoy llegamos al puerto

Por fin oh navecilla

No volverá tu quilla

Hacia el mundo otra vez (Poema 3, estrofa 1)

Un mundo amenazante que tanto la novicia como la profesa han sabido vencer:

Pisaste ya del mundo Tú fuiste combatida

La serviz orgullosa De tormentas terribles

Y la corona ermosa Y entre angustias horribles

Que adorna el vencedor Pensaste sosobrar. (Poema 3, estrofa 3)

Veo sobre tu frente

Querida hermana mía

Brillar en este día

Con gloria y con honor. (Poema 5, estrofa 1)

Un mundo que, reconocen las autoras, está en constante tensión con la vida en el claustro. En tono imperativo exclama sor Cayetana:

Mundanales pasiones no intenten

Perturbar esta unión un momento

Ni se atreva su fétido aliento

Este asilo inocente invadir. (Poema 2, estrofa 8)

Otra autora, recogiendo los ataques a la vida en la clausura que circulan en la sociedad porteńa, opta por transmitir cuál es la representación de la monja que se construye en "el siglo": 
El mundo en su delirio

Fanática te llama

Desventurada esclava

Como piensas así.

No ves que eso es engaño

No ves que esa es locura

La delicia más pura

Disfrutarás aquí.

Así se expresa el mundo

$Y$ es porque no conoce

Que el verdadero goce

Sólo se encuentra en Dios. (Poema 5 estrofas 4, 6)

En oposición a este mundo hostil, la vida religiosa en el huerto cerrado se representa -en el imaginario cristiano- como el puerto seguro, el lugar de aguas tranquilas, en el que los votos de pobreza, obediencia y castidad -las obligaciones a las que las religiosas se han comprometido por la profesión-, a modo de anclas, las mantendrán a salvo y las ayudarán a transitar el camino hacia la perfección:

Con amarras bien fuertes

Estáis asegurada

Ya en la playa deseada

Hallaste tu placer.

(Poema 3, estrofa 2)
Progresad en la exacta obediencia Progresad en la estrecha pobreza Progresad en la blanca pureza Y en amor de Jesús progresad. (Poema 2, estrofa 3)

Una perfección que se debía buscar a lo largo de toda la vida y que consistía en la más absoluta unión con Jesucristo, su amado Esposo. ${ }^{34}$

En el monasterio de las dominicas de Buenos Aires, tanto en el ritual de toma de hábito y en el de profesión, como en los poemas

${ }^{34}$ Sobre el tema de las emociones en los monasterios de monjas de Hispanoamérica véase Rosalva Loreto López, "El amor divino y la mística hispanoamericana. Una aproximación a las representaciones emocionales de la feminidad barroca”, en Amor e Historia. La expresión de los afectos en el mundo de ayer, coord. Pilar Gonzalbo Aizpuru, 275-298 (México: El Colegio de México, 2013). 
escritos por las monjas, se exacerba el carácter amoroso de esta relación. Una relación entablada entre el alma y Dios, cuyas raíces se encuentran en el pasaje bíblico del Cantar de los Cantares y se usó desde la Edad Media como una de las bases de la espiritualidad. ${ }^{35}$ En el siglo xvi fue traducido al español por fray Luis de León, ${ }^{36}$ e inspiró el Cántico espiritual de san Juan de la Cruz. En él, el fraile carmelita alude directamente al sentimiento a través de la alegoría nupcial, para exponer mediante el lenguaje poético el inefable amor de Dios y verter en conceptos inteligibles sus propias experiencias místicas. ${ }^{37}$ Santa Teresa de Jesús, quien también recurre a esta alegoría en Las Moradas y en su obra poética, habla de "grosera comparación". Sin embargo, como ella misma reconoce, no hay otra mejor para explicar, para dar a entender lo inefable de esta relación entre las religiosas y Jesucristo. ${ }^{38}$

Las monjas catalinas de Buenos Aires -que muy probablemente conocían las obras mencionadas- ${ }^{39}$ también se apropian de este lenguaje erótico para expresar la unión amorosa entre su alma y Dios, a la que aspiran. Lo hacen a través del único lenguaje posible, el del amor humano:

\section{Ven dulce Jesús mío \\ Dire en tiernas endechas \\ Ven gozarte en las flechas \\ Que tu amor me clavó.}

${ }^{35}$ En los monasterios femeninos del siglo xiII, la actualización del Cantar de los cantares, -que proponía a la monja como Esposa de Jesucristo- llegó sobre todo a través del Speculum virginum. La exégesis del Cantar introdujo el lenguaje erotizado para hablar con Dios en los ámbitos de la religiosidad femenina, y, sin duda, modeló actos como el de Hildegarda de Bingen -siglo XII-, quien en su monasterio vestía a sus monjas de seda blanca y coronas para mostrar así mejor que ellas eran las novias de Cristo. Véase Victoria Cirlot y Blanca Garí, La mirada interior, 40.

${ }^{36}$ Fray Luis de León, Poesías. Cantar de los cantares (Buenos Aires: Losada, 1998), 199-220.

${ }^{37}$ San Juan de la Cruz, Obras completas, $7^{\mathrm{a}}$ ed. (Madrid: Editorial Apostolado de la Prensa, 1958).

${ }^{38}$ Santa Teresa de Jesús, Obras completas, Moradas Séptimas (Madrid: Biblioteca de Autores Cristianos, 1989), 441.

${ }^{39}$ Tanto las obras de san Juan de la Cruz como las de santa Teresa de Jesús se encuentran en la biblioteca del Monasterio de Santa Catalina de Sena, biblioteca donada por su fundador, don Dionisio de Torres Briceño. 
Ven pronto no te tardes

Que te aguardan mis brazos

Recíprocos abrazos

Nos daremos los dos. (Poema 3, estrofas 6 y 7 )

Las "flechas" y el "gozo", presentes en el Cántico de san Juan de la Cruz, aluden, según él mismo expresa, a los "toques que fecundan el alma y el corazón de inteligencia y amor", ${ }^{40}$ a la "llamada de amor". Una metáfora que Teresa de Ávila retoma en su poema "Mi amado para mî"

Hirióme con una flecha
Enherbolada de amor
Y mi alma quedó hecha
Una con mi Criador. ${ }^{41}$

Y que otras monjas de Hispanoamérica también eligieron para expresar su profundo amor: la Madre María de Jesús Josefa de la Concepción Castillo (1671-1742) de Tunja, Colombia, escribió:

\author{
El abla delicada \\ Del amante que estimo \\ Miel i leche distila \\ Entre rosas y lirios \\ Su meliflua palabra
}

${ }^{40}$ San Juan de la Cruz, Obras completas, 604. Según afirma Ramón Mujica: "El concepto de Dios como 'cazador divino' que hiere ontológicamente el Alma para hacerla cautiva, presa o prisionera del amor proviene del filósofo y beato catalán Raimundo Lulio (ca. 1235-ca. 1315), del teólogo dominico alemán y escritor místico Meister Eckhart (1260-1327) y de Juan Ruusbroec. Ramón Mujica Pinilla, Rosa Limensis. Mistica, politica e iconografía en torno a la patrona de América (Lima: Fondo de Cultura Económica, 2001), 142-143. Durante el Renacimiento italiano pasa a formar parte del arte y del vocabulario neoplatónico de poetas y filósofos seculares. En el Siglo de Oro español, santa Teresa vincula las "heridas de amor" causadas por el Esposo oculto a un cierto tipo de melancolía demoníaca, que al entremezclar una pena activa con un amor ardiente, despierta el alma y la hace ingresar a la sexta morada del Castillo Interior.

${ }^{41}$ Santa Teresa de Jesús, Obras completas, 502. 
Corta como rocío

I con ella florese

El corasón marchito. ${ }^{42}$

Sor Catalina de Jesús Herrera (1717-1795) del Monasterio de Santa Catalina de Sena, Quito, Ecuador, optó por expresarlo del siguiente modo:

\author{
En la soledad \\ busqué a mi querido \\ y lo divisé \\ allá muy metido \\ por unos resquicios \\ hacia lo escondido \\ donde los amantes \\ viven más unidos \\ con estrechos lazos \\ en vínculo unidos \\ yo me penetré hasta verme \\ en su propio nido. ${ }^{43}$
}

El amor a Jesucristo, esposo, dueño y modelo de las religiosas, debía inspirar todas sus acciones. A él entregaban, abandonaban, su voluntad. ${ }^{44} \mathrm{Tal}$ como lo expresó en Buenos Aires sor Cayetana del Santísimo Sacramento:

${ }^{42}$ Afecto 4, "El abla delicada" reproducción fotográfica del manuscrito de la Madre Castillo en Kathryn Joy McKnight, The Mystic of Tunja, 175.

${ }^{43}$ Poema reproducido en Rossi de Fiori et al., La palabra oculta, 459. El poema ha sido tomado de la edición realizada por Alfonso A. Jerves, op, Secretos entre el alma y Dios o Autobiografía de la Vble. Madre sor Catalina de Jesús Ma. Herrera, religiosa de Coro del Monasterio de Sta. Catalina de Sena de Quito, descifrada y sacada directamente de su original autógrafo (Quito: Ed. "Santo Domingo", 1950), XI-XIII.

${ }^{44}$ Sobre el abandono a la voluntad de Dios, el olvido de sí, el anonadamiento, una actitud fundamental en el camino espiritual de las religiosas véase Carlo Ossola, "Caminos de la mística: siglos XVII-Xx", en Mistica y creación en el siglo XX. Tradición e innovación en la cultura europea, ed. Victoria Cirlot y Amador Vega, 13-62, especialmente 30-33 (Barcelona: Herder Editorial, 2006). 
Yo seguiré tus pasos

A doquiera que fueras

Has de mí lo que quieras

Tuya es mi voluntad.

(Poema 3, estrofa 8)
Sí caro dueño mío

Con el alma lo digo

Yo viviré contigo

Yo moriré por ti. (Poema 3, estrofa 17)

La voz de Jesucristo es introducida en los poemas de las religiosas porteñas a través de un coloquio. El mismo Cristo se propone como modelo por seguir, por ser imitado:

Jesús

Supuesto que a seguirme

Estás tan decidida

Preciso es que tu vida

La conformes a mí. (Poema 3, estrofa 10)

Un modelo difícil de imitar, ya que implicaba aceptar la cruz, pero acreedor de recompensas. Un hecho que las monjas de la ciudad porteña tienen presente y expresan reiteradamente en sus poemas.

— la vida religiosa es considerada un bien supremo, y en consecuencia dan "el parabién" a la ingresante:

Recibidlo también de nosotras

Que sabemos valorar tu fortuna

Comparada a la cual no hay ninguna

Ni se puede más bien obtener. (Poema 2, estrofa 6)

— un estilo de vida que brinda la posibilidad de disfrutar de sosiego y amor, tan necesarios para observar la soledad interior:

Edén santo mansión deliciosa

Te saludo cien veces y más

En ti solo se goza la calma

Y se tiene la suerte de amar. (Poema 8, estrofa 3) 
- que también supone el disfrute de determinadas gracias compartidas sólo en la intimidad-, como consecuencia del estatus de esposa de Jesucristo:
Él te coloca en su esfera
De sus esposas queridas
Hizo gracias repetidas
Que sólo saben los dos. (Poema 4, estrofa 4)
— y la promesa de la salvación, la gloria eterna:

[Progresad] En la dulce, la bella, la hermosa

Caridad que a Jesús enamora

Progresad, progresad desde ahora

Que con ella a la gloria entrarás. (Poema 2, estrofa 11)

Dos de los tres poemas escritos a comienzos del siglo xx, exactamente en 1903 (poemas 7 y 9) tienen algunas particularidades que los distinguen del resto del corpus analizado: no son poemas originales, sino copia de otros - una práctica vigente en el ámbito conventual $-{ }^{45}$ escritos a comienzos de la década de 1860 (poemas 4 y 3 respectivamente), ${ }^{46}$ sus "autoras", sor Mercedes de Santo Domingo Olmos y sor María Dominga del Rosario Correa, provienen de Córdoba, ingresan casi al mismo tiempo y son electas para el oficio de priora en varias oportunidades. Al final de cada poema agregan un diálogo de tono bufonesco, protagonizado por dos "pícaros", personajes ficcionales, a través de los cuales comentan el texto poético y muy probablemente intentan poner una nota de humor en la reunión conventual a la que estaba destinada la escritura, ${ }^{47}$ destruyen-

${ }^{45}$ A esta modalidad hace referencia Nieves Baranda Leturio, "Cantos al sacro epitalamio", 290; "Producción y consumo poéticos”, 183.

${ }^{46}$ En el poema 9, la "autora" saltea dos estrofas del original -poema 3- y cambia dos versos en la estrofa 3.

${ }^{47}$ Asunción Lavrin (Brides of Christ, 329) comenta que en un monasterio de México, al final de una obra de teatro se incluye la presencia de un indio que habla español con dificultad, una figura introducida con la clara intención de divertir a la audiencia a través de esta intervención cómica. En España, sor Francisca de Santa Teresa (1654-1709) 
do a la vez cualquier vestigio de vanidad o vanagloria. Ambos agregados finalizan con una palabra en latín: "Nemo" -nadie- y "Amen" -en verdad, que conste-.

Después leyeron éstos y continuaron

—QQué tiernos estos versos! —¿Qué los critique? .... iNunca!

Suspiros son de una alma

Pues que no siendo tonto

Que aquí no encuentra calma

Que sólo vive en Dios

Su autor, como tú, pronto

Me había de hablar así:

Mas porque no se sienta

Su autor enaltecido

Se los critiques pido

Por más que sin razón.
"Tu crítica majadera

Pedancio no me altera

Mas mucho pesar me diera

Si te gustaran a ti".

Amen (Poema 9)

¿Estamos en presencia de un humor diferente, más jovial de las cordobesas, tal vez ausente entre las monjas porteñas? La última estrofa refiere al epigrama Pedancio de Leandro Fernández de Moratín, dramaturgo y poeta español (1760-1828), supuesto autor de una obra en que le ayudaban varios amigos:

Pedancio, a los botarates

Que te ayudan en tus obras

No los mires ni los trates

Tú te bastas y te sobras

Para escribir disparates.

¿O es que a comienzos del siglo $\mathrm{xx}$ ya no hacía falta asumir esa actitud por momentos combativa, desafiante, de mediados del siglo

también escribe "de chanza", según sus propias palabras, y pone el acento en lo cómico, sabe reírse de sí misma y saca a relucir un saludable sentido del humor basado en los juegos de palabras y en el doble sentido de las mismas. $\mathrm{Al}$ respecto véase Ma. Carmen Alarcón Román, "La producción poética de Sor Francisca de Santa Teresa (1654-1709): entre la cotidianidad y la espiritualidad", en Letras en la celda. Cultura escrita de los conventos femeninos en la España moderna, ed. Nieves Baranda Leturio y Ma. Carmen Marín Pina, 357 (Madrid y Frankfurt: Iberoamericana-Vervuert, 2014). 
anterior y los poemas pasan a cumplir una función lúdica? Por el momento sólo tengo respuesta para esta última pregunta. En efecto, hacia fines del siglo XIX comienza a advertirse en Argentina, como en otros países latinoamericanos, una mejor predisposición de las elites culturales y políticas hacia el catolicismo y una mejoría en las relaciones entre el Estado y la Iglesia. A pesar de que en 1884 el presidente de la Nación expulsa al delegado apostólico Luis Matera, las elites observan con mayor simpatía a la religión tradicional, y desde la década de 1880 entre algunos intelectuales surge la idea de que la nación no nace de un mero contrato político, sino que constituye ante todo una comunidad cultural y religiosa. Y en este contexto, la Iglesia tiene bastante que ofrecer. ${ }^{48}$

\section{Conclusiones}

En medio de una sociedad que busca reconfigurarse, en pleno periodo de redefiniciones y reacomodamientos que involucran un proceso de secularización, un periodo que culmina en 1862 con la instauración de la República Argentina unificada y tres años más tarde con la creación de la arquidiócesis de Buenos Aires, las monjas dominicas de clausura toman la palabra y optan por expresarse a través de la poesía. En un contexto social adverso interpelan al discurso hegemónico que las acusa de víctimas, esclavas y que caracteriza la profesión religiosa como un sacrificio inútil.

Escriben una serie de poemas - de los que se han conservado nueve- en torno al ingreso a la clausura, a la profesión solemne y al sentido de ser monja. Un corpus compuesto en su mayor parte en la década 1860; tres de los poemas pertenecen a un periodo posterior, los primeros años del siglo xx. La opción de las monjas por el anonimato sólo nos permite conocer el nombre de tres de sus autoras.

Son poemas escritos con la intención de homenajear a las ingresantes en el día de la toma de hábito y a las novicias en ocasión de su

${ }^{48}$ Sobre el contexto en el periodo 1880-1910 véase Roberto Di Stefano, Ovejas negras. Historia de los anticlericales argentinos (Buenos Aires: Editorial Sudamericana, 2010): 252-254. Véase también Miranda Lida, Historia del catolicismo en la Argentina: entre el siglo XIX y el XX (Buenos Aires: Siglo XXI editores, 2015), 31-35. 
profesión solemne. Es poesía de mujeres para mujeres, escritas para una audiencia homogénea -mujeres que comparten un mismo código semántico aprendido durante el noviciado, a través de las lecturas del oficio divino y de los sermones- y que, por lo tanto, seguramente comprenden las metáforas y las alegorías que constantemente evocan.

Sin embargo, la lectura del corpus permite constatar que hay otros motivos. En medio de una sociedad que les es hostil, también escriben para reconocerse, para liberarse, para explicarse, para hablar de sí, para socializar, para desplegar la intimidad sin miedo, pues, saben que estos textos poéticos circularán exclusivamente en la clausura, que serán leídos o recitados en un ambiente íntimo, acotado, una vez finalizadas las ceremonias públicas que tenían lugar en el templo conventual.

Son poemas de experiencia directa de la vida consagrada que completan los ritos de tránsito, del cruce del umbral, ritos que buscan hacer inteligible lo inefable: el paso de común mortal a mujer consagrada, esposa de Jesucristo, fortalecen de este modo la adquisición de esta nueva identidad; escritos para conmover; para moldear el carácter de las profesas; para hablar de Jesucristo y con Jesucristo, el esposo y modelo por imitar.

Retoman elementos de una tradición poética que, iniciada en la Edad Media, culmina en santa Teresa de Jesús y san Juan de la Cruz, cuyas respectivas obras las autoras muy probablemente han leído o cuya lectura han escuchado, pues, copias de ambos textos se encuentran en la biblioteca conventual desde el periodo fundacional en el siglo XVIII.

Estamos ante poemas tal vez escritos en la intimidad de la celda que muestran muy buen nivel de autoconocimiento en torno a los motivos desplegados: el sentido de ser monja, el rechazo del mundo, la vida en la clausura, las obligaciones y las recompensas, los combates y los placeres cotidianos que trae aparejada esta opción y el modelo por seguir. Motivos que expresan a través de un estilo íntimo y afectuoso logrado al optar por una posición discursiva que muestra a las autoras y a las destinatarias como "hermanas", miembros de una misma familia. 
De los nueve textos que constituyen el corpus analizado, siete comparten las características enunciadas. Pero dos de ellos, escritos en 1903, se distinguen claramente de los anteriores: llevan el nombre de sus "autoras", que resultan no ser tales, pues, se trata de una copia de dos poemas de la serie anterior. Es más, hacia el final de cada uno de ellos encontramos un agregado de tono bufonesco, escrito con la clara intención de burlarse de su obra, que destierran de este modo todo vestigio de vanidad. Eran otros tiempos. A comienzos del siglo xx, aparentemente, había espacio para el humor.

Si bien nunca se imprimieron, todos los poemas han sido copiados con muy clara caligrafía, en folios sueltos, sin numerar, y celosamente custodiados en el Archivo del Monasterio de Santa Catalina de Siena de Buenos Aires. Un claro indicador del valor histórico y testimonial que a través de los años las religiosas han dado a estos textos, que hoy nos permiten conocer qué pensaban las monjas de clausura de sí mismas y cómo entendían su propio mundo en el momento cuando la sociedad porteńa buscaba reconfigurarse y el oficio de ser monja había llegado a ser considerado "un sacrificio inútil" por algunos sectores sociales.

\section{ApÉNDICE}

Poemas del Monasterio Santa Catalina de Sena, Buenos Aires, 1861-1903

\begin{tabular}{|c|c|c|c|c|c|}
\hline Título del poema & $\begin{array}{l}\text { Toma de } \\
\text { habito / } \\
\text { profesión }\end{array}$ & Fecha & Autora & $\begin{array}{l}\text { Destina- } \\
\text { taria }\end{array}$ & $\begin{array}{l}\text { Pecularie- } \\
\text { dades }\end{array}$ \\
\hline $\begin{array}{l}\text { 1. Eres virgen pru- } \\
\text { dente }\end{array}$ & Profesión & $?$ & ? & ? & \\
\hline $\begin{array}{l}\text { 2. Sor Mariana mi } \\
\text { querida hermana }\end{array}$ & $\begin{array}{l}\text { Toma de } \\
\text { hábito }\end{array}$ & 1872 & $\begin{array}{l}\text { Atribui- } \\
\text { da a sor } \\
\text { Cayetana } \\
\text { del Smo. } \\
\text { Sacra- } \\
\text { mento } \\
\text { Albín y } \\
\text { Villegas }\end{array}$ & $\begin{array}{l}\text { Sor Maria- } \\
\text { na de Jesús } \\
\text { Brown }\end{array}$ & \\
\hline
\end{tabular}


Poemas del Monasterio Santa Catalina de Sena, Buenos Aires, 1861-1903 (continuación)

\begin{tabular}{|c|c|c|c|c|c|}
\hline Titulo del poema & $\begin{array}{l}\text { Toma de } \\
\text { habito / } \\
\text { profesión }\end{array}$ & Fecha & Autora & $\begin{array}{l}\text { Destina- } \\
\text { taria }\end{array}$ & $\begin{array}{l}\text { Pecularie- } \\
\text { dades }\end{array}$ \\
\hline 3. A Sor María Ana & $\begin{array}{l}\text { Toma de } \\
\text { hábito }\end{array}$ & 1861 & $\begin{array}{l}\text { Atribui- } \\
\text { da a sor } \\
\text { Cayetana } \\
\text { del Smo. } \\
\text { Sacramen- } \\
\text { to Albín y } \\
\text { Villegas }\end{array}$ & $\begin{array}{l}\text { Sor María } \\
\text { Ana de Je- } \\
\text { sús Piñero }\end{array}$ & \\
\hline $\begin{array}{l}\text { 4. A mi querida her- } \\
\text { mana Sor María Ana } \\
\text { de Jesús }\end{array}$ & Profesión & 1862 & ? & $\begin{array}{l}\text { Sor María } \\
\text { Ana de Je- } \\
\text { sús Piñero }\end{array}$ & \\
\hline $\begin{array}{l}\text { 5. Pisaste ya del } \\
\text { mundo }\end{array}$ & Profesión & $?$ & ? & $?$ & \\
\hline $\begin{array}{l}\text { 6. Llegó por fin } \\
\text { el día }\end{array}$ & Profesión & ? & ? & ? & \\
\hline $\begin{array}{l}\text { 7. A mi querida } \\
\text { hermanita Sor Ma. } \\
\text { Ana de Jesús Sacra- } \\
\text { mentado }\end{array}$ & Profesión & 1903 & $\begin{array}{l}\text { Sor } \\
\text { Mercedes } \\
\text { de Santo } \\
\text { Domingo } \\
\text { Olmos } \\
\text { (Córdoba) }\end{array}$ & $\begin{array}{l}\text { Sor Ma. } \\
\text { de Jesús } \\
\text { Sacra- } \\
\text { mentado } \\
\text { Olmos } \\
\text { (Córdoba) }\end{array}$ & $\begin{array}{l}\text { copia de } \\
\text { poema } 4\end{array}$ \\
\hline $\begin{array}{l}\text { 8. A mi querida } \\
\text { hermanita Sor María } \\
\text { Cecilia de Sta. Rosa }\end{array}$ & $\begin{array}{l}\text { Toma de } \\
\text { hábito }\end{array}$ & 1901 & $\begin{array}{l}\text { Atribui- } \\
\text { da a sor } \\
\text { Cayetana } \\
\text { del Smo. } \\
\text { Sacramen- } \\
\text { to Albín y } \\
\text { Villegas }\end{array}$ & $\begin{array}{l}\text { Sor Ma. } \\
\text { Cecilia de } \\
\text { Martínez } \\
\text { Calderón }\end{array}$ & \\
\hline $\begin{array}{l}\text { 9. Canto de María de } \\
\text { Jesús Sacramentado el } \\
\text { día de su profesión }\end{array}$ & & 1903 & $\begin{array}{l}\text { Sor María } \\
\text { Dominga } \\
\text { del Rosa- } \\
\text { rio Correa } \\
\text { (Córdoba) }\end{array}$ & $\begin{array}{l}\text { Sor Ma. de } \\
\text { Jesús } \\
\text { Sacra- } \\
\text { mentado } \\
\text { Olmos } \\
\text { (Córdoba) }\end{array}$ & $\begin{array}{l}\text { copia de } \\
\text { poema } 3 \\
\text { con varian- } \\
\text { tes menores }\end{array}$ \\
\hline
\end{tabular}

Fuente: Archivo del Monasterio Santa Catalina de Siena, San Justo, Provincia de Buenos Aires, Argentina 
Bibliografía

Alarcón Román, Ma. Carmen. "La producción poética de sor Francisca de Santa Teresa (1654-1709): entre la cotidianidad y la espiritualidad". En Letras en la celda. Cultura escrita de los conventos femeninos en la España moderna, ed. Nieves Baranda Leturio y Ma. Carmen Marín Pina, 357. Madrid y Frankfurt: Iberoamericana-Vervuert, 2014.

Arenal, Electa y Stacey Schlau. Hispanic Nuns in their Own Works. Albuquerque: University of Mexico Press, 1989.

Armacanqui-Tipacti, Elia. Sor María Manuela de Santa Ana. Una teresiana peruana. Cuzco: Centro de Estudios Regionales Andinos "Bartolomé de las Casas". 1999.

Ayrolo, Valentina, María Elena Barral y Roberto di Stefano. Catolicismo y secularización. Argentina, primera mitad del siglo XIX. Buenos Aires: Editorial Biblos, 2012.

Baranda Leturio, Nieves. "Cantos al sacro epitalamio o sea pliegos poéticos para las tomas de velo. Deslindes preliminares". Bulletin Hispanique, tomo 113(1) (junio 2011): 269-296.

. "Producción y consumo poéticos en los conventos femeninos". Bulletin Hispanique, tomo 115(1) (junio 2013): 165-183.

Baranda Leturio, Nieves y Ma. Carmen Marín Pina, eds. Letras en la celda. Cultura escrita de los conventos femeninos en la España moderna. Madrid y Frankfurt: Iberoamericana-Vervuert, 2014.

BEER, Francis. Women and the Mystical Experience in the Middle Ages. Woodbridge: The Boydell Press, 1992.

Bénassy-Berling, Marie Cécile. "Actualidad del sorjuanismo (1994-1999)", Colonial American Historical Review 9(2) (2000): 277-292.

Braccio, Gabriela. "Una ventana hacia otro mundo. Santa Catalina de Sena: primer convento femenino de Buenos Aires". Colonial Latin American Review 9 (2) (2000): 187-211.

Bremond, Henri. Plegaria y poesía. Buenos Aires: Editorial Nova, 1947.

Bruno, Cayetano, sdb. Historia de la Iglesia en la Argentina. 12 vols. Buenos Aires: Editorial Don Bosco, 1966-1981. 
Chartier, Roger. El mundo como representación. Historia cultural: entre práctica y representación. Barcelona: Gedisa, 1995.

Cirlot, Victoria y Blanca Garí. La mirada interior. Escritoras misticas y visionarias en la Edad Media. Barcelona: Ediciones Martínez Roca, 1999.

Cirlot, Victoria y Amador Vega, eds. Mistica y creación en el siglo XX. Tradición e innovación en la cultura europea. Barcelona: Herder, 2006.

De Certeau, Michel. La escritura de la historia. México: Universidad Iberoamericana, 1993.

. La invención de lo cotidiano. 1 Artes de hacer. México: Universidad Iberoamericana, 1996.

Di Stefano, Roberto. Ovejas negras. Historia de los anticlericales argentinos. Buenos Aires: Editorial Sudamericana, 2010.

Di Stefano, Roberto y Loris ZanatTa. Historia de la Iglesia argentina. Desde la Conquista hasta fines del siglo XX. Buenos Aires: Grijalbo Mondadori, 2000.

EIch, Jennifer. The Other Mexican Muse. Sor Maria Águeda de San Ignacio (1695-1756). Nueva Orleans: University Press of the South, 2004.

Fraschina, Alicia. Mujeres consagradas en el Buenos Aires colonial. Buenos Aires: EUDEBA, 2010.

- "Reinventar la clausura. Una tarea de las monjas dominicas de Buenos Aires en el siglo XIX". Itinerantes. Revista de Historia y Religión (1) (2011): 91-115.

. "El proceso de secularización en los monasterios de monjas y en la Casa de Ejercicios y Beaterio de Buenos Aires, 17501865". En Catolicismo y secularización. Argentina, primera mitad del siglo XIX, coords. Valentina Ayrolo, María Elena Barral, Roberto di Stefano, 39-64. Buenos Aires: Editorial Biblos, 2012.

Glantz, Margo. Sor Juana Inés de la Cruz: ¿Hagiografia o autobiografia? México: Grijalbo, unam, 1995.

GrAZIOSI, Elisabetta. "Scrivere in convento: devozione, encomio e persuasione nelle rime delle monache fra Cinque e Seicento". En Donna, disciplina, creanza cristiana dal XVI al XVII secolo. Studi e 
testi a stampa, ed. Gabriella Zarri, 303-331. Roma: Edizioni di Storia e Letteratura, 1996.

JuAn de la Cruz, San. Obras completas. $7^{\mathrm{a}}$ ed. Madrid: Editorial Apostolado de la Prensa, 1958.

Kordic Riquelme, Raïssa. Epistolario de sor Dolores Peña y Lillo (Chile, 1763-1769). Madrid, Frankfurt y Main: Universidad de Navarra, Iberoamericana-Vervuert, 2008, 504-511.

LaboA, Juan María. Historia de la Iglesia. IV: Época contemporánea. Madrid: Biblioteca de Autores Cristianos, 2002.

Lavrin, Asunción. Brides of Christ. Conventual Life in Colonial Mexico. Stanford: Stanford University Press, 2008.

. "Los senderos interiores de los conventos de monjas". Boletín de Documentos Históricos. 3a Época (30) (enero-abril 2014): 6-21.

Lavrin, Asunción y Rosalva Loreto López, eds. Monjas y beatas. La escritura femenina en la espiritualidad barroca novohispana. Siglos XVII y XVIII. México: Universidad de las Américas-Puebla, Archivo General de la Nación, 2002.

LaVrin, Asunción y Rosalva Loreto López. Diálogos espirituales. Manuscritos femeninos hispanoamericanos. Siglos XVI-XIX. México: Universidad Autónoma de Puebla, Universidad de las AméricasPuebla, 2006.

León, fray Luis de. Poesías. Buenos Aires: Losada, 1998.

LIDA, Miranda. Historia del catolicismo en la Argentina: entre el siglo XIX y el XX. Buenos Aires: Siglo XXI editores, 2015.

Loreto López, Rosalva. "El amor divino y la mística hispanoamericana. Una aproximación a las representaciones emocionales de la feminidad barroca". En Amor e historia. La expresión de los afectos en el mundo de ayer, coord. Pilar Gonzalbo Aispuru, 275298. México: El Colegio de México, 2013.

McKnight, Kathryn Joy. The Mystic of Tunja. The Writings of Madre Castillo, 1671-1742. Amherst: University of Massachusetts Press, 1997.

Morant, Isabel, dir. Historia de las mujeres en España y América Latina, vol. III. Madrid: Cátedra, 2006, 692-719.

Mujica Pinilla, Ramón. Rosa Limensis. Mistica, politica e iconogra- 
fí en torno a la patrona de América. Lima: Fondo de Cultura Económica, 2001.

Muriel, Josefina. Cultura femenina novohispana. México: Universidad Nacional Autónoma de México [1ª ed. 1982], 1994.

Myers, Kathleen Ann. "Crossing Boundaries: Defining the Field of Female Religious Writing in Colonial Latin America". Colonial Latin America, Historical Review 9(2) (2000): 151-165.

Ossola, Carlo. "Caminos de la mística: siglos XVII-Xx". En Mistica y creación en el siglo XX. Tradición e innovación en la cultura europea, ed. Victoria Cirlot y Amador Vega, 13-62. Barcelona: Herder, 2006.

Petroff, Elizabeth. Medieval Women's Visionary Literature. Nueva York: Oxford University Press, 1986.

Río, Nela. "Me hizo pensar cosa no pensada. La poesía de sor Leonor de Ovando (1548?-1612?)". En Diálogos espirituales. Manuscritos femeninos Hispanoamericanos. Siglos XVI-XIX, ed. Asunción Lavrin y Rosalva Loreto López, 386-419. México: Benemérita Universidad Autónoma de Puebla, Universidad de las Américas-Puebla, 2006.

Rossi de Fiori, Íride María, Rosanna Caramella de Gamarra y Helena Fiori Rossi. Primera escritura femenina en la República Argentina. Poemas del Carmelo de Córdoba (1804). 2a ed. Salta: Biblioteca de Textos Universitarios, 2000.

Rossi de Fiori, Íride María, Rosanna Caramella de Gamarra, Soledad Martínez de Lecuona y Helena Fiori Rossi. La palabra oculta. Monjas escritoras en la Hispanoamérica colonial. Salta: Universidad Católica de Salta, Editorial Biblioteca Textos Universitarios, 2008.

Scotт, Nina. "Escritoras hispanoamericanas del siglo xix". En Historia de las mujeres en España y América Latina. Vol. III, dir. Isabel Morant, 692-719. Madrid: Cátedra, 2006.

Segura Graiño, Cristina, ed. La voz del silencio. Fuentes directas para la historia de las mujeres (siglos VIII-XVIII). Madrid: Asociación Cultural Al-Mudayna, 1992.

SuRTz, Ronald. Writing Women in Late Medieval and Early Modern Spain. The Mothers of Saint Teresa of Avila. Filadelfia: University of Pennsylvania Press, 1995. 
Teresa de Jesús, Santa. Obras completas. Madrid: Biblioteca de Autores Cristianos, 1989.

UdaOndo, Enrique. Reseña histórica del Monasterio de Santa Catalina de Sena de Buenos Aires. Buenos Aires: Talleres Gráficos San Pablo, 1945.

ZARRI, Gabriella, ed. Donna, disciplina, creanza cristiana dal XVI al XVII secolo. Studi e testi a stampa. Roma: Edizioni di Storia e Letteratura, 303-331. 